\title{
Cyber-Consciousness Between Self Perception and Body Image
}

\section{Cristina-Georgiana Voicu}

Romanian Academy, Iaşi, Romania

\section{Email address:}

voicucristina2004@yahoo.fr

\section{To cite this article:}

Cristina-Georgiana Voicu. Cyber-Consciousness Between Self Perception and Body Image. Psychology and Behavioral Sciences. Vol. 4, No. 2, 2015, pp. 58-63. doi: 10.11648/j.pbs.20150402.14

\begin{abstract}
This paper deals with the ontology of mind and its objective reality of being in certain states of self modified by consciousness, which implies a loss of differentiation between physicality and object. By entering the self, the ego becomes conscious to itself. Through this paper we propose to explore a new and less studied concept, i.e. the "virtual self". The issue of creating another identity in the online environment is quite complex, and has an extremely surprising impact, since the individuals' motivations are different, not being any pattern in this regard. For example, in case of some individuals the self-consciousness changes (also become a kind of cyber-consciousness) are just a variation of the same figures which reveal the repressed aspects of real life, being no link to the real self.
\end{abstract}

Keywords: Self Perception, Otherness, Body Image, Cyber-Consciousness, Virtual Self

\section{Introduction}

While we are lately witnessing a true inflation of the discourse on the body, to the detriment of the soul (as well as about space at the expense of time), the body is rather an aesthetic object with complex social meanings, or an economical object to be exploited and to be fed. Being an interface of communication and of self interaction with the others, what matters more than ever in terms of bodily representations as a means of mediation between cultural communication and society, is the shape, and therefore, the so-called consumer society usually requires the image of a seductive body. As for that in this paper, I want to go beyond cultural stereotypes in understanding the body image.

Focusing on the perception of self and body by extension is not randomly, this being sustained both by the ability of cyber-consciousness to take new forms, and, especially, the imposition of a subject who seeks for itself and examines its anxieties in relation to itself and reality, fully assuming its otherness. Thus, from a cognitive point of view, the self is trying to understand the relationship between being and non-being.

Body-symbol, body-text, body-agent, absent body, body-interaction are all instances of the same Body, shaped by ontological and epistemological different interests. Talking about body implies, in fact, a reification of the self through the body. One limitation is the identification of the body as a cultural mediator and also as a catalyst for various types of modern mentality as an image / perception vector of the self.

The reversed perception of objective reality is associated with a spatial cleavage that highlights just the outside deferred simultaneity of bodily inside. The social structure has its roots in the functional and efficient rationality and the culture within the evidence of self-enhancement. In this regard, the mind does not always come from an isolated epistemic consciousness.

The cyber-consciousness defined as the oppositional consciousness is a false consciousness; it is actually a cyber-feeling, because the false image on self inevitably faces the rigors of the reality.

The concept of "false consciousness" is not just extremely eloquent, since it is not only about that an individual ignores his/her very essence and nature or that simply thinks differently. Normal individual whose image perceptions are more or less reasonable, having a balanced self may rationally exist with his/her own image. And not because he/she would not accept his/her real self but because he/she wants to be believed that he/she is an individual endowed with those qualities which he/she does not hold, but he/she most aspires at. Such an individual confuses his/her own reality with an 
illusory ideal of the self. But this self substitution does not consciously occur, but becomes an unconscious construction ${ }^{1}$. With the setting of this false consciousness, the latter becomes a truth. The incapacity of a fair self introspection thus leads to alienation towards reality, equivalent of psychosis, if we accept that any false consciousness is progressively made on a repressed self-consciousness.

The body is relevant in the current context of cultural studies. Between loathing the human body and various forms of bodily narcissism, the visionary body is still perceived as a unified whole, impossible to be "dissected". The body image has, therefore, an ambivalent nature, being in a meta-space, between the notions of tradition and modernity, and the concepts of identity and cultural otherness. This paper argues the critical analysis of the continuous updating of body representations in the sense of combining the physical aspects with those related to technology, making the virtual bodies integrative brands of identity / otherness having their origins in various cultural codes.

\section{Methodology}

The new emerging technologies place the human subject, ontologically analyzed in relation to both the objective reality and the virtual world, processed in cyberspace (cyberspace and virtual reality system in its various present stances). The user's body and mind provides his/her contact with both worlds (despite their meanings of some cyber-theorists on reflecting the disembodiment in cyberspace). Moreover, the "upgraded" human subject can be perceived as ambivalent, both as a technological extension of the body and its consciousness in cyberspace, and as a technological immersion of the virtual world within the user's physical world. The relationship between reality and virtuality is an irreversible one, the space of reality being neither substituted nor simulated by cyberspace.

In terms of methodology, this paper seeks to "recover" the dimension of reality as well as the relationship between body and consciousness within the globalizing context of the new virtual technologies, calling the relationship between human identity and physical/digital space. Inside both worlds, the human being is like the extension of both. According to the phenomenological approach of the real space, the body consists in "placing" the subject to the real world. The body topology becomes physiological and psychological/cognitive, physical, dynamic, relational and identitarian, sensorial and perceptual belonging to both physical matter and consciousness. So, the embodied experience is equivalent with self perception; to have a body means to belong to a certain space, so being in a body does not mean to exist in the world, but to belong to it. The human body is always in the world, so that the body itself or the objectified body cannot

1 In this case, the body image that defines the individual does not coincide with the body scheme mentioned by the French psychoanalyst Françoise Dolto [1]. Being a foundation of narcissism/egolatry, it is par excellence unconscious: the symbolic embodiment of the desired individual. exist in particular. On the contrary, this becomes an intentional subject located in space, so connected to the world and interacting with the environment. The body thus becomes the center of any human experience through his/her perceptions, realizing its own ontological world. The body appears as a lived experience within the objective reality, simultaneously with the space that intrinsically belongs to the body.

The body-subject experience in the real world is first an experience of the space that occurs through gestures, movements and actions. The body is not a spatiality of situation but of position, because it is situated in space and it is not positioned; the body is equally space (physical space) and perception of space (reality space). Far from being just a fragment of space, the body is the space foundation through which it exists. The body extension in the world is followed by movement and action or motion - as an original intentionality - showing the fact that the body itself is not in space, but it lives in space. So, the lived experience is necessarily made by the body: the individual's consciousness is always incarnated, this being at the intersection between mind and body, both placed in the real physical space. Therefore, the subjective consciousness is a perceptual living level, and therefore, the bodily existence has the self perception as its certainty. In turn, the perception is incorporated / built, providing the measure of lived experience.

The self perception is not just the result of the impact of reality on the body because, even if the body distinguishes from the world in which it exists, this is not separate from the world. Finally, the perception is considered a summary of the complex interference between the subject that perceives and its being: through bodily perception, the space comes back into existence. From the same phenomenological experience of the individual within the objective reality space, within the new digital technologies of the virtual space (virtual reality, cyberspace, digital space, etc.) the experience of a motrico-sensory corporality takes shape. In this regard, the creators of digital technologies are increasingly trying to involve the human senses through the process of immersion in cyberspace. In this process, the user's consciousness of cyberspace is an embodied consciousness of the body subject, who perceives the virtual world by immersing in it; the relationship of the subject with the cyberspace becomes complex in terms of intentional extension of the action, of motion or orientation within the virtual world.

\section{Discussion}

The body of the digitized subject underlies at subjectivity interface as through corporality, cyborg entity type accesses the virtual world. Necessarily, the physical nature of the body manifests in the virtual space as materiality, not just only because of the virtual reality technology hardware etc., but also because of the integrated body images / perceptions. On the one hand, in cyberspace, the subject perceives the environmental response to its bodily actions; on the other hand, when during the experiments involving virtuality, the user physically acts through body, the body movements are causing 
those within virtual space. In the virtual world, the physical body is simultaneously part of the real world and that of virtuality, the material-physical movements and the organs of perception having virtual consequences, while the virtual perception still depends on the physical human actions.

Both the mainstream culture, and the popular one of the last decades tracked the new (post)human dimensions in the virtual space, especially those of digital performance or hypermedia. In comparison with the individual, who is located in the objective reality space and who has immediate access, the subject within the virtual environment has mediated access (by prosthesis and interface) to the latter. The cyborg body thus becomes the existential foundation of the virtual world and an agent of experience inside. Even if 'to exist in the virtual world' does not denote the ontological contingency, but the ontological or simulated mediation, the cyber experience is lived like a virtual existence in this case. The cyberspace is thus explored by the experiences of the technological and biological body to fusion, and thus the cyborg subject is connected to the online virtual world either by prosthesis or interface of the organic area. What is still important is that the experience of virtual reality and of cyberspace does not submit to the real laws (distance, weight, gravity experiments, density), but it has its own characteristics (flight experience, floating, swimming, etc.). Therefore, a new type of experience is shaped within virtuality (e.g. the experience of object fluidity or the immeasurable speed of movement).

Digital technologies of the body assume the physical and physiological limits of the body entity and of experience failure. However, ironically, the insertion of the prosthesis in the body or extending the corporal capacities is achieved by means of the body itself. Being a body within the virtual space means to live through bodily perceptions. The exaggerations felt by the organic-psychical body in this so-called "post-biological" era still occur in the extended context of the human body. The human body is not "obsolete" or "outdated" as it is conveyed through some theorists and designers of present technology point of view, on the contrary, it is always "updated" / "upgraded". By integrating the subject in cyberspace the human body is subjectively experienced and it cannot be replaced by technology. Human subjectivity cannot be neglected in terms of organic remodeling, prosthesis or its interface, no matter how much digital ideology would exist.

In this section of the paper, I try to emphasize the ontological importance ${ }^{2}$ regarding the experimentation of the

2 Unlike inhibition manifested in several centers of the brain related to self-consciousness and subjective consciousness, there is more activity that emphasizes the consciousness of a physical / objective reality different from that associated with body consciousness. To support these ideas there were empirical arguments for non-intentional states of consciousness supported by the lack of thought and the stream of thought related to the self [2]. There are also arguments that experiments to find neural correlations of consciousness could be wrong thus overcoming the ontological subjectivity. Recent research conducted using neural brain imaging helped discover the essence of the brain related to the consciousness of a more objective reality when subjectivity is inhibited and a self dissociation is achieved, leading to a feeling of unity (oneness) of a changed self. Researchers in neuroscience observed a striking absence of neuronal activity in the parietal lobe of objective reality spaces and of virtuality. Although it can be considered as being of a cyborg, the individual's identity can be found by accessing the existence of digital body. Moreover, there is a cybernetic connection of bodies and subjectivities by capitalizing each bodily entity. The organic metaphor of the human existence remains valid. The bodies' network in cyberspace generates a mobile, connected, proximal and multiplicative identity; both the bodies' individuality as well as their connectivity is a process of virtual spacing of self perception.

Essentially, the individual is immersed in the virtual world as a body-mind unit as his perception and conscience are incarnated. The virtual space changes subjectivity, causing it to become conscious of its bodily-material both in real and virtual world. To have this double consciousness (what I would call, cyber-consciousness) is synonymous with the joint reflection between the organic and technological ${ }^{3}$. In cyberspace, the subject moves and is guided, feels, perceives the body, so there is a relation of the prosthetic or interfaced body to cyberspace pending the symbiosis between the organic and technological. So, the subject bodily-sensorial and mentally sinks within the virtual reality system, the bodily senses integrating the mind into the digital space. Total immersion of the subject back in cyberspace is the foundation of its virtual experimentation in virtuality: the connected senses to the interface are incorporated so as the bodily tangible sense not to dissipate in the virtual environment of the identitarian and spatial fluidity. Although the body representations become fluid in virtuality, their permeable flows are physically maintained both by the materiality of technology, as well as the body itself. Virtual technologies do not lead to the disappearance of corporality, but to the inclusion of the body back in cyberspace.

Therefore, the virtual-body relationship is rather a symbiosis achieved by the awareness of location and orientation, at a perceptual and experiential level. Whether the individual's consciousness connected to virtual technologies is split between two worlds, it remains marked by the body-mind integrity. Finally, the spaciousness of the cybernetic body manifests itself in the world of virtuality through organic-technological fusion between the embodied physical matter and the subject's mind. Mapping the space-body becomes ambivalent towards a de-spatialization and a respatialization or, in Deleuze and Guattari's terms, to deterritorialization and reterritorialization. The body as spatialization refers the destruction previous to building. Thus, as de-spatialization, the virtual body signifies the destruction

the brain determining the bodily self image and distinguishing the self and the non-self. There is a diffuse system in the brain, such as the locus coeruleus which plays an important role in the level of subjective consciousness of the self and in that of the awareness as individual with a body consciousness and a strong sense of self determination.

3 Cyber-consciousness is defined as "simulating the human brain with computer software and technology". See more at: http://www.quickanddirtytips.com/tech/web/what-is-cyberconsciousness\#sthash. WfbisFK8.dpuf, accessed on February 6, 2015. 
of the body image by immersion and simulation. As respatialization, the virtual body equals with the biological rediscovery of the tech body in cyberspace. So, the relationship space between the body and space manifests in both ways: the body experience as space (space corporalization) and the space experience through body (body spatialization). Between these two coordinates of flow and ebb type of the virtual subject, the body-spatialized paradigm operates in terms of mechanical-organic moving fusion of the worlds, of human and technology, as well as of joining the body edges, thus giving meaning to self perception starting from the theory of inneism ${ }^{4}$ (from an ontological perspective).

In cyberspace, there is dissolution of the body, an "evaporation" of the real physical foundation so the individuals should be part of the virtual. Some sociologists as Philip Breton state that in cyberspace, the body becomes a real burden and the body is separated from space where the "action" takes place (e.g. search for information, using the chat, email, Internet etc.). Moreover, within modern society the subject can remotely act without the need for physical presence. In this respect, it can be argued that in cyberspace the body has no intrinsic or extrinsic value; moreover, it is even rejected.

On the other hand, it is suggested that technology is actually an extension of the body and thus the individuals can more easily reach the place where once they were more difficult to penetrate it. This "body rejection" because of the virtualized space appears as an extreme attitude; even there were some attempts of "digitalizing" the physical body. One such example is the use of avatar that allows users to associate a similar digital personality in physical terms.

Another extremely important concept in cyberspace is a-synchronicity. In the communication of objective reality, the other's reaction is very important for how the conversation will go; in a conversation, the feedback is very important in the process of self-revelation. When in the world of virtuality, communication is not performed in real time (so it is an asynchronous communication), such as the blog or e-mail (the reaction or response may be received after a longer period of time, as the one who must give the answer will choose), then an uninhibited effect is produced. This feed-back gap can determine, on the one hand, a greater depth of conversation, but it can also lead to a duplicitous behavior in relationships with others. Equally important is the exaggeration of the psychological effect of introspection, the individuals having all sorts of "talk" in their imagination, since there they feel free to express all sorts of things they would not say in real life.

4 “[...] Thought, according to which any truth is known as of the birth. Our heart visited the 'sky of the ideas' before being incarnated in a body. Of our alive, one must practice the reminiscence to remember again the truths which we observed. All is innate thus, but one must do a personal work of recollection." http://wikipedia.qwika.com/fr2en/Inn $\% \mathrm{C} 3 \% \mathrm{~A} 9$ isme, accessed on February 2, 2015. Moreover, the theory of inneism renders the mind and consciousness the opportunity to live an indefinite period of time in a new virtual world. It, therefore, tries to sketch, performing various scientific observations, the only rational way by which self-consciousness could survive in the future to the death of the body.

\section{Results}

Self-identity is rather symbolic, immaterial and apparently unnecessary. The anxiety of securing the interiority (innerness), the need of self defense precedes the self perception and self-knowledge. In my view, the interest for the self outlines the curiosity towards self perception. The self perception justifies the deep fusion with its own identity [6]. Defining the "self" simultaneously occurs with that of the "Other." An individual exists to the extent that the other exists as well, only that the latter exists in a different way than the former. "Living" his/her own identity as a person is not comparable with the perception of Other's identity. In the real world, we cannot deny the presence of the other, his/her stream of consciousness being inaccessible to others, this remaining just as a tangible manifestation of some abstract cognitive categories.

This desire of testing different identities can be met with little effort by multiplication. The consequences of multiple identities existence were studied in detail by Sherry Turkle [3]. She supports this game of multiplication is extremely dangerous because the self can lose its consistency under the pressure of values exchange and of role play. Furthermore "the true identity" no longer includes the assumed virtual identities; it is only a body image disorder [4]. Thus, not multiplicity, but the lack of physicality is threatening the virtual identity. There is a risk that this virtual identity should not coincide with the real identity in any way. This is one of the pathological cases of otherness - i.e. alienation or an inner mechanism called cognitive dissonance - that is, the happening of an inner conflict, because an individual has two views at once which do not only support, but they sometimes exclude one another. In the absence of an immobile landmark, the self-consciousness dissipates, the netizen dissolving within the virtual field [5].

Following this idea, we cannot speak of an identity without a body, because it cannot be understood that two mental experiences were lived by one and the same subject. Undoubtedly, the virtual practices involve a distancing from the body, because whatever the action - communication, navigation, symbolic manipulation - this is not accompanied by perceptions of motion, or mobility in cyberspace. As a result, the virtual identity would be deeply threatened by de-corporalization. This principle, which I might call the "principle of consciousness-body", demonstrates that it is not the body that essentially counts, but its mental representation, i.e. "body image" [7] subject to the imagination and which can be changed in the virtual environment without harming the undiscovered virtual identity.

In these conditions, if we agree that the bodily absence does not jeopardize the virtual identity of the self, we must admit the idea that communication with the other could be missed. The facility of virtual contact, despite the physical distance between the cyber-users suggests the idea of aggression on the Other's space and the exercise of an invading authority of his/her intimate space. The speed, the power of penetration and the avalanche of information are those responsible for 
weakening the identity by the other's invasion of his/her own space. These virtual instruments of the Other's "aggression" are not closely related to the measurable indices of information flows, but to those multifaceted strategies of handling identity.

Identity is made by interpellation, the individual having a predetermined symbolic place within the social space (both spatial and temporal) for practices imposed by society. The interpellation works in cyberspace through interactions within virtual communities. It will not follow the same rules that we got accustomed in the real world because the virtual hierarchies are not coagulated into a fixed structure, they are still in an early phase and the social symbolic spaces do not exist before the act of interpellations, but they define themselves by this very act. The virtual interpellation of the other is manifested as a manipulation rather than as an aggression.

In the absence of some semantic trademarks of physicality/corporality, the virtual identity is based on narrative features that give tone, texture and proportion to a message. Virtual identity is designed to capture the Other's attention, as a spellbound observer, who inhibits his/her own wish to express. This successful "marketing" of an identity derives from the suitable choice of the role on the virtual scene. The "Other" does not expose, but proposes that version that he/she thinks could be suitable for incitement.

Often, in the context of various speculations about the virtual identity of the self and the plurality of assumed identities by their multiple roles where the self perception is projected by the virtual field, the netizen is trying to project $\mathrm{him} /$ her from the universe of the self to that of virtuality. By its virtual character, this outer position endangers the individual of losing his/her self-consciousness. In this respect, by the already undertaken studies it was demonstrated how the netizen's self-consciousness increasingly becomes vulnerable, up to volatilization [5].

If the first part of the paper on the relationship between the self perception and the Other I problematized the loss of self-identity in relation to otherness, in the second part of the analysis I placed the virtual horizon in another issue area, that of weakening the self perception/consciousness. The netizen is simultaneously part of more virtual communities than the "implanted" individual into reality. More than this, the netizen can conventionally multiply his/her one identity through the roles offered by cyberspace, simultaneously adopting the identities of a: cyber-surfer, cyber-communicator, cyber-builder, cyber-user and so on.

On the other hand, the multiple virtual identities that the individual currently adopts can be addressed through cultural mediation. The cultural conventions and the heterogeneous discursive practices are essential in cyberspace for taking part in the creation process of interpellation. The identity thus begins to change (the netizen becomes what he/she really is) by the manner of addressing / interpellation of the other or how to respond to others, by interpellation.

In conclusion, the dynamic of building virtual identities is founded on the principle of interpellation. Through interpellation, the others structure identity and the self makes others' identity. To belong to more cyber-communities means that the self is subject to several interpellations. Thus, an extraordinary dialectics arises between the opposing interpellations and the adhesion, between accepting the virtual self and the rejection of the other's discursive stylistics. The consequence of this exposure is the awareness of a virtual allowing world compared to the real world constrained by rules and less permissive laws, harder to tolerate by the pressures of the society. The isolation within virtual independence seems to be the only chance to the netizen. It can be concluded that the virtual existence develops a so-called capacity of resistance to the real, the cyberspace being nothing more than a simple introduction to the real space.

\section{Conclusions}

Although this issue of self perception and body image arouses different opinions, one thing is very clear: the cybernaut changes the self-reporting through interpellation. Not eventually, the virtual technology is addressing to consciousness by different instances of otherness, so that the self projection [8] in other situations enhances the multiplicity of the individual. Therefore, coordinating various personalities of the self is possible only through relativism which does not allow its stagnation into a certain identity. The requirement limiting the switch from an original virtual position to the pathological stance of otherness is just the individual's creative function that allows running the distancing and differentiation from the virtual space [9] through its symbolic actions designed for reality.

\section{Acknowledgements}

This paper is supported by the Sectoral Operational Programme Human Resources Development (SOP HRD), financed from the European Social Fund and by the Romanian Government under the contract number POSDRU/159/1.5/133675.

\section{References}

[1] Dolto, Françoise. Imaginea inconştientă a corpului. Bucureşti: Editura Trei, 2005, pp. 123-128.

[2] Strawson, G, "Phenomenology and ontology of self". In D. Zahavi (ed.), Explaining the self: philosophical and psychological advances in consciousness research. Amsterdam, Philadelphia: John and Benjamin Pub Co, 2000, pp. 164-190.

[3] Turkle, Sherry. Life on the Screen: Identity in the Age of the Internet. New York: Simon and Schuster, 1995, pp. 23-27.

[4] Vanderwolf, C.H., The Evolving Brain. The Mind and the Neural Control of Behavior. New York: Springer, 2007, pp. 19-32. Retrieved on February 4, 2015 from http://link.springer.com/book/10.1007/978-0-387-34230-6. 
[5] Mihalache, Adrian. "Ciber-conştiinţa: O identitate fără trup". Noema, Vol. I, nr. 1, 2002, pp. 132-141.

[6] Hermans, H. J. M. "The dialogical self: Toward a theory of personal and cultural positioning". Culture \& Psychology, 2001, 7: 243-281.

[7] Penelhum, Thomas. Survival and Disembodied Existence. London: Routledge and Kegan Paul, 1970.
[8] Fasching, Wolfgang. "Consciousness, self and meditation", Phenomenological Cognitive Sciences, 2008, 7: 463-483.

[9] Belk, R. W. "Extended self in a digital world". Journal of Consumer Research, 2013, 40: 477-500. 